\title{
Franz Kafka, leitor de Heinrich von Kleist
}

\section{Eduardo Manoel de Brito*}

\begin{abstract}
Franz Kafka's critical fortune is rich in relating the writer's way to construct his own narrative associated sometimes with themes treated in Kleist's literary works. In support of my reflections upon this issue, I have focused on the essays by two Brazilian literary critics who have revealed aspects of this relation: Otto Maria Carpeaux and Luiz Costa Lima. Many decades separate one from the other; however, both seem to have confluence lines on Kafka's approach to Kleist's work. After presenting aspects of Kleist-Kafka relation based on a critical background, I looked for references about Kleist in Kafka's non-literary texts, in order to establish a foundation for what is said by the critics mentioned in this essay.
\end{abstract}

Keywords: Franz Kafka; Heinrich von Kleist; German literature; literary critics.

Resumo: A fortuna crítica sobre Franz Kafka é pródiga em relacionar o modo de o escritor construir sua narrativa e algo dos próprios temas com a produção kleistiana. Como uma forma de refletir sobre isso, atentarei para dois críticos que expuseram aspectos desta relação em solo brasileiro: Otto Maria Carpeaux e Luiz Costa Lima. Distados várias décadas, os dois parecem, contudo, possuir certas linhas de confluência na abordagem kleistiana da obra de Franz Kafka. Após expor aspectos da relação Kleist-Kafka nos recortes da crítica brasileira, buscarei referências a Kleist em textos não literários de Kafka com a finalidade de encontrar neles um fundamento para o que é afirmado pelos críticos tratados neste ensaio.

Palavras-chave: Franz Kafka; Heinrich von Kleist; literatura alemã; crítica literária.

Stichwörter: Franz Kafka; Heinrich von Kleist; Deutschsprachige Literatur; Literaturkritik.

\section{A relação Kleist e Kafka em recortes da crítica brasileira}

Otto Maria Carpeaux, já no seu ensaio publicado em livro em 1942 (o primeiro texto inteiramente dedicado a Franz Kafka produzido no Brasil), afirma o seguinte: "Feita a abstração de alguns pontos de contacto com Heinrich von Kleist, o Kleist do ensaio Sobre o teatro de bonecas, e com E. T. A. Hoffman, a presença de Kafka na literatura alemã é simplesmente ocasional." (CARPEAUX 1942: 158)

Como se depreende, a menção a Kleist no texto dedicado a Kafka é bastante genérica, o que, de resto, se repetirá em boa parte da crítica que fez a mesma relação. Um tal enfoque não se repetirá, contudo, no ensaio publicado em livro no ano de 1960 fazendo o caminho inverso, ou seja, citando Kafka num texto dedicado a Kleist:

\footnotetext{
" Doutor em Letras, Literatura Alemã, título conferido pelo Programa de Pós-graduação em Língua e Literatura Alemã da FFLCHUSP.edubrito@usp.br
} 


\begin{abstract}
Sabendo que a "existência humana não tem fundo debaixo de nossos pés", Kleist não admitia ilusões. É de um realismo implacável, contando as coisas mais monstruosas ou, pelo menos, inesperadas como se fossem lógicas e naturais. É esse estilo seco que inspirava tanta admiração a Franz Kafka, leitor constante das novelas de Kleist. Mas o estilo não foi o único motivo dessa admiração.

As influências decisivas no pensamento de Kleist foram Rousseau e Kant. Do primeiro aprendeu que temos perdido o Paraíso; do outro que nunca mais voltaremos para lá. Mas não seriam estes, também, os problemas de Kafka? Os personagens de Kafka, assim como os de Kleist, estão desorientados no mundo. Procuram a verdade redentora e encontram o erro fatal. Mas há uma diferença: os personagens de Kafka parecem joguetes na mão de forças incompreensíveis. Os personagens do dramaturgo Kleist são "caracteres": nesta vida "sem fundo" guardam coerência ferrenha que nenhum acontecimento é capaz de quebrar. (CARPEAUX 1960: 47-48)
\end{abstract}

Carpeaux marca em seguida que Acontecimento (fazendo questão de justificar o uso da maiúscula) é a marca da produção literária kleistiana: determinados Acontecimentos irrompem num cotidiano comum e dão um rumo inesperado e quase surreal à vida dos seus personagens. Apesar de ele, neste sentido, não fazer a relação entre Kafka e Kleist, essa seria uma outra ponte a ligar os dois escritores tratados neste ensaio. De qualquer modo, é possível resumir a relação Kafka-Kleist, segundo os pontos de vista de Carpeaux, aos seguintes aspectos: Kafka admirava o "estilo seco" de Kleist; ambos teriam aprendido que o Paraíso foi perdido pelos homens e que não seria possível voltar para ele e, por fim, ambos criaram personagens "desorientados no mundo".

Com relação a aspectos de imbricação entre a produção literária de Kleist e de Kafka, assim podem ser resumidas as opiniões expressas por Luiz Costa Lima no seu livro Limites da voz: Kafka:

1) $\mathrm{O}$ modo de conduzir o assombroso com rapidez magnética distingue o procedimento kleistiano-kafkiano dos românticos alemães (LIMA 1993: 16);

2) Kafka abalaria a "casa forte do eu" e se filiaria a uma tradição da qual faz parte, entre outros, Kleist. (LiMA 1993: 61);

3) Uma "mesma ausência de um centro de gravidade orientador das ações individuais" encontrada em Kafka está presente em Kant. Contudo, levando em conta que não há como fazer esta relação direta, encontra-se entre Kant e Kafka a figura de Kleist, que teria exposto isso em sua obra. (LiMA 1993: 94);

4) A "instabilidade semântica extrema" de Kafka, mas também de Kleist, Flaubert e de Beckett "teatrólogo e romancista", faz com que eles produzam algo num "encaminhamento oposto do que fora o romance clássico". (LIMA, 1993: 97);

5) "[...] ao período em que a perda da crença na substancialidade absoluta da Lei regente do mundo ainda não dava lugar à experiência de vertigem em que excederiam Kleist e Kafka”. (LIMA 1993: 123)

6) "Que significa dizer que a ilimitação da arbitrariedade da Lei resultaria de um crescimento que lhe seria inerente? Significa que, a exemplo de Kleist, Kafka é dominado pelo terror que resulta de a ambição da razão não corresponder aos resultados do entendimento." (LIMA 1993: 162). 
Como se pode perceber, a admiração de Kafka em relação a Kleist é mencionada - ao menos nas obras utilizadas neste ensaio e escritas pelos dois críticos - apenas por Carpeaux. A razão disso está, muito provavelmente, nos objetivos e nas formas diferentes utilizadas pelos dois críticos na elaboração de seus trabalhos. Os dois textos de Carpeaux foram escritos originalmente para jornal e, apenas, posteriormente publicados sob a forma de livros e - ao menos o primeiro artigo - tinha a intenção explícita de apresentar o autor ao público brasileiro, expondo aspectos variados da produção literária kafkiana. O texto de Lima corresponde à sua interpretação acadêmica da obra de Franz Kafka e está, certamente, em diálogo com toda uma tradição crítica anterior, apesar de ele ignorar completamente qualquer estudo crítico produzido no Brasil a respeito do autor tcheco. De qualquer modo, fica claro que Lima se abstém de instaurar alguma relação entre Kafka e Kleist como uma atitude consciente do autor tcheco, ou seja, o crítico brasileiro não menciona nem uma admiração nem algum tipo de tentativa kafkiana de seguir um modelo kleistiano de literatura. Não cabe neste ensaio uma crítica à qualidade dos dois textos no que diz respeito às análises e interpretações da obras tanto de Franz Kafka quanto de Heinrich von Kleist. Intentando algum tipo de síntese dos dois críticos, poder-se-ia apresentar os seguintes pontos:

1) A afirmação de que Kafka admirava o estilo seco de Kleist é citada por Carpeaux, mas também pode ser sentida, enquanto modo de escrever kafkiano, na expressão "rapidez magnética" para conduzir o assombroso, ou seja, no modo de ambos os escritores não fazerem floreios na descrição dos Acontecimentos, por mais assombrosos que estes sejam.

2) Relacionando a questão da Lei ao Divino, é possível afirmar que tanto Kafka quanto Kleist não têm mais esperança de algum dia retornar ao Paraíso perdido. Também o terror, apontado por Lima, de que a ambição da razão não encontraria correspondente nos resultados do entendimento encontra ecos aí, visto que é na consciência de que o Paraíso se perdeu que o homem também perderia a fé de que razão e conhecimento teriam uma relação direta. Em outras palavras, é no Paraíso perdido que o homem perde o acesso ao conhecimento que denomina e organiza o mundo, tornando-o passível de entendimento.

3) Ambos os críticos apontam uma desorientação dos personagens criados tanto em Kafka quanto em Kleist. Aí também se encontraria a afirmação de Lima de que ambos os escritores abalariam a "casa forte do eu"; pois seria também na desorientação dos personagens que isso se manifestaria.

Restaria para que os pontos de confluência entre Kafka e Kleist fossem intercambiáveis para as duas críticas produzidas no Brasil a questão da "instabilidade semântica extrema". Contudo, deixarei tal crítica de lado porque Lima a faz tendo como referências reflexões de Harold Bloom e de Hannah 
Arendt (cf. LimA 1993: 97) e, além disso, as imbricações se resumem aí não à relação direta entre Kafka e Kleist, senão que se estendem para outros escritores. De qualquer modo, a expressão "extrema" para caracterizar a instabilidade semântica parece ter mais uma função retórica, emprestando ao texto de Lima uma adjetivação de cunho personalista.

O próximo passo será rastrear em textos não literários de Kafka um fundamento para o que foi afirmado - e repetido por outros tantos críticos brasileiros e estrangeiros - a respeito de Kafka ser um admirador da obra de Kleist e de, por conta de uma certa filiação aos seus termos e modos de escrita, ser possível encontrar aspectos kleistianos nos textos kafkianos. Naturalmente os dois críticos citados - mas principalmente Lima - buscaram fundamentar suas considerações muito mais na produção literária de Franz Kafka no sentido estrito, do que nos comentários feitos pelo próprio escritor tcheco. Mas creio que retomar tais pontos seria retornar ao tantas vezes dito sem ir às fontes fornecidas pelo próprio escritor e essa é a justificativa para a opção feita no presente ensaio.

\section{Referências a Heinrich von Kleist em textos de Franz Kafka}

O primeiro contato do escritor tcheco com Kleist deu-se no ambiente escolar, precisamente no seu tempo de Gymnasium (entre 1893 e 1901), como seria de se esperar, visto que Kafka estudou numa instituição alemã e Kleist já era um escritor do cânone da literatura alemã. Não há, contudo, nenhum comentário feito a tais leituras ou a reflexões de Kafka a respeito deste período (cf. Hermes/ JOHN/ KOCH/ WIDERA 1999: 18).

Uma primeira menção documentada neste sentido é encontrada no dia 4 de janeiro de 1911, ano do centenário de morte de Kleist. Kafka contou, neste dia, para Max Brod e Oskar Baum, seus amigos, que lera Heinrich von Kleist para suas irmãs e assinala: "Sie weinen. 'Das sind jetzt meine besten Leistungen" (cf. HERMES/ JOHN/ KOCH/ WIDERA 1999: 62). Não é mencionado qual o livro Kafka leu, mas a ênfase dada pelo escritor parece ter sido tão marcante que não ele, mas Max Brod registrou isso num diário. $\mathrm{O}$ orgulho com o qual Kafka teria narrado o evento a Brod e a Baum, parece ser conseqüência da reconhecida capacidade de Franz Kafka em fazer leituras públicas de textos (seus e de outros autores), amplamente registrada na fortuna crítica do autor tcheco. Ainda em 1911, Kafka enviava um postal para o seu amigo e futuro testamenteiro literário com o seguinte texto: 
wie in eine alte Schweinblase. Damit es nicht $\mathrm{zu}$ arg wird und weil ich es mir vorgenommen habe, gehe ich jetzt in die Lucerna. (KAFKA 1998: 87)

Esta seria, segundo a organização de Max Brod para a produção literária de Franz Kafka, a primeira vez que o autor tcheco mencionaria Heinrich von Kleist por escrito. O comentário "Kleist sopra-me como em uma bexiga de porco velha" pareceria não ser uma afirmação tão elogiosa, não fosse ele escrito por Kafka, pois no seu caso pode ser interpretado como o resultado de uma leitura que produziria incômodo e que lançaria o leitor para uma reflexão crítica e - por que não? - angustiosa do mundo. Em 20 de fevereiro de 1911, Kafka anota em seu diário que está lendo as cartas da juventude de Kleist, no volume Leben, Werke und Briefe (Leipzig 1910) (cf. Hermes/ JOHN/ KOCH/ WiderA 1999: 64). No final do mesmo ano, por ocasião das homenagens pelos 100 anos da morte de Kleist, Kafka escreveria uma resenha das Anekdoten de Kleist, organizadas por Julius Bab (cf. HERMES/ JOHN/ KOCH/ WIDERA 1999: 75), que é reproduzida na íntegra abaixo:

\footnotetext{
Das ist ein Anblick, wenn die großen Werke, selbst bei willkürlicher Zerteilung, aus ihrem unzerteilbaren Innern immer wieder leben, dann vielleicht ganz besonders in unsere trüben Augen schlagend. Darum hat jede Einzelausgabe, welche die Aufmerksamkeit ein- für allemal an ein Begrenztes hält, ihr tatsächliches Verdienst, gar wenn sie, wie diese Sammlung Kleist'scher Anekdoten, eine neue Einheit respektiert und so den Umfang des Kleist'schen Werkes förmlich vergrößert. Sie vergrößert ihn selbst dann, wenn wir alle diese Anekdoten schon kennen sollten, was aber zur Freude vieler durchaus nicht der Fall sein muß. Der Kenner wird es natürlich erklären können, warum manche dieser Anekdoten in verschiedenen Gesamtausgaben, selbst in der Tempelausgabe, fehlen; die Nichtkenner wird das nicht verstehen, dafür sich aber desto fester an diesen neuen Text halten, den ihm der Verlag Rohwohlt in Klarem Druck und ernsthafter Ausstattung (besonders das etwas getönnte Papier scheint uns passend) für diese Kleingkeit von 2 Mark liefert. (KAFKA 2004: 148)
}

A partir do uso da expressão "Anblick" (traduzível como fenômeno), é possível afirmar que Kafka se mostra empolgado com o lançamento das Anekdoten de Kleist. Contudo, ele faz críticas a trabalhos que possuam uma divisão arbitrária de textos ("willkürlicher Zerteilung"), que ficariam melhores se fossem lidas em sua forma original interna indivisível („unzerteilbaren Innern"). Cumpre lembrar aqui a diferença em alemão de Sammlung e "Sämtliche Werke": no primeiro caso, trata-se de uma coletânea ou seleção de textos (portanto, com caráter arbitrário e dependendo dos gostos literários do organizador) e no segundo, trata-se de uma organização das obras completas, permitindo, então, uma leitura mais dirigida pelo próprio leitor. O comentário kafkiano está de acordo com o seu próprio apuro em organizar os seus textos, insistindo em determinadas organizações e relutando em publicar obras com caráter claramente inconcluso ou cujas partes não estejam conectadas. $\mathrm{O}$ comentário feito por Kafka sobre o recorte feito da obra kleistiana para 
publicação tende para o negativo, principalmente quando ele coloca em contraste as leituras possíveis dos conhecedores e desconhecedores dos textos e ao comentar - já no final do seu ensaio - a qualidade do papel usado, parece fazer uma ironia, como se esse fosse um dos aspectos mais importantes do lançamento. De qualquer modo, muito pouco é dito sobre a qualidade em si dos textos. De qualquer modo, o livro resenhado inclui-se entre as grandes obras ("die großen Werke") e é um texto que quando relido ou lido pela primeira vez produz resultados diferentes.

A menção seguinte a Kleist viria numa carta também enviada a Max Brod e datada de 10 de julho de 1912 e corresponderia tão somente a um comentário sobre a pertinência de incluir um estudo seu sobre Anekdoten de Kleist na revista "Höhe des Gefühls". Ainda no mesmo ano, numa carta enviada a Ernst Rowohlt, proprietário da Rowohlt-Verlag, datada de 07 de setembro de 1912, Kafka pede que o editor utilize para publicar o seu Betracbtung (primeiro livro publicado por Kafka) algo do mesmo "tipo de papel das Anedotas de Kleist" ("etwa nach der Art des Papiers der KleistAnekdoten”) (KAFKA 1998: 104).

Outras menções a Kleist feitas por Kafka, neste ínterim, podem ser encontradas nas cartas enviadas a Felice, as quais não foram incluídas na organização das cartas feitas por Max Brod, que compilou as cartas enviadas às mulheres que passaram pela vida de Kafka em volumes únicos (Briefe an Felice e Briefe an Milena). Em duas entradas com o termo Kleist, encontramos um comentário mais longo e uma menção simples. Quanto ao comentário mais longo, eis o excerto com a referência:

\footnotetext{
Gestern abend habe ich Dir nicht geschrieben, weil es über Michael Kohlhaas zu spät geworden ist (kennst Du ihn? Wenn nicht, dann lies ihn nicht! Ich werde Dir ihn vorlesen!), den bin ich bis auf einen kleinen Teil, den ich schon vorgestern gelesen hatte, in einem Zug gelesen habe. Wohl schon zum zehnten Male. Das ist eine Geschichte, die ich mit wirklicher Gottesfurcht lese, ein Staunen faßt mich über das andere, wäre nicht der schwächere, teilweise grob hinuntergeschriebene Schluß, es wäre etwas Vollkommenes, jedes Vollkommene, von dem ich gern behaupte, daß es nicht existiert (...). (KAFKA 2003: 291-292)
}

Kafka afirma-se, portanto, "tomado de uma admiração após a outra" quando lê o texto kleistiano Michael Kolhaas e, no excerto, a frase final deixa claro o quanto ele colocava Kleist acima de outros escritores, como algo praticamente único na literatura na sua forma de escrever perfeita ("jedes Vollkommene").

No mesmo ano, Kafka lê um informe sobre a morte de Kleist e comenta isso com Brod, que anota a informação no próprio diário (cf. 
HERMES/ JOHN/ KOCH/ WidERA 1999: 102). Em setembro deste ano Kafka comenta com Felice Bauer e aqui insiro a menção simples referida acima - a respeito da possibilidade de um casamento - que ele se sente em consangüinidade com quatro escritores (ele usa a expressão Menschen): Grillparzer, Dostojewski, Kleist e Flaubert, "hat nur Dostojewski geheiratet und vielleicht nur Kleist, als er sich im Gedränge äußerer und innerer Not am Wannsee erschoß, den richtigen Ausweg gefunden“ (cf. HERMES/ JOHN/ KOCH/ WiderA 1999: 106-107). No final deste ano, Kafka lê numa apresentação beneficente Michael Kolhaas (certamente uma seleção feita por ele) (cf. HERMES/ JOHN/ KOCH/ WIDERA 1999: 110).

Apenas em 1921, já debilitado pela tuberculose, Kafka voltaria a mencionar Kleist nas correspondências organizadas por Max Brod e, na ocasião, faria tão somente um pedido: que Ludwig Hardt, um leitor público de textos literários e que também fizera leituras públicas de textos kafkianos, incluísse em seu programa de leitura (num dia em que Kafka estaria presente) anedotas kleistianas. (KAFKA 2003: 358).

De posse de tais informações compiladas dos textos kafkianos, pode-se organizar as menções feitas a Kleist da seguinte forma:

1) Kafka lia freqüentemente, pública ou privadamente, textos de Kleist.

2) Há uma predileção evidente de Kafka (que atravessa uma década em menções) pelas Anekdoten e pelo texto Michael Kolhaas (que ele leu “umas dez vezes”). Kafka afirma ler este último com um verdadeiro temor de Deus (Gottesfurcht), uma expressão, inclusive, presente tanto na tradição judaica quanto na cristã. Com respeito ainda a este texto, Kafka usa a expressão admiração (Staunen), afirmando que a conclusão dele não tinha nada de falho, senão que seria perfeito ("es wäre etwas Vollkommenes, jedes Volkommene").

3) Kleist seria um escritor cuja organização dos textos deveria ser respeitada para uma compreensão mais correta de sua produção literária (lembrando da resenha feita às Anekdoten).

\section{Conclusão}

A mencionada admiração de Franz Kafka a Heinrich von Kleist é referendada inúmeras vezes pelos escritos de Franz Kafka, com especial predileção pelas Anekdoten e por Michael Koblhaas. Mas não apenas uma admiração, senão que Kafka via na escritura do outro autor como perfeita ("Volkommen"), termo que aparece, ao menos, duas vezes nas suas anotações sobre a obra kleistiana. A perfeição do autor estaria tanto na sua composição interna (retomando as considerações sobre Michael Kolhaas), quanto na apreciação em conjunto, como seria o caso das Anekdoten. Além desse aspecto 
mais literário, haveria uma aproximação no campo mais pessoal entre Kafka e Kleist (incluindo outros escritores), no que se refere à sua dificuldade de se conciliar com a idéia do casamento.

De posse de tais informações, fica mais fácil fundamentar algumas leituras kleistianas das obras de Franz Kafka, pois não é difícil enxergar na perfeição intentada pelo autor tcheco aquilo que ele admirava na obra de Kleist: a escritura acabada e sem arestas. Tal perfeição (que tem sempre a ver com a forma acabada e com um apuro formal) aponta, também, para a insatisfação do próprio Kafka em relação aos seus textos e a sua intervenção constante em todas as fases de produção (incluindo a escolha do papel!).

Portanto, ainda que se possa afirmar que em alguns momentos a crítica tenha relacionado Kleist a Kafka de modo superficial, apenas repetindo o que já vinha sendo dito, é possível encontrar nos próprios textos (cartas, comentários e diários) de Kafka fundamentos para estudos de cunho mais interpretativo de tal relação. Desse modo, os aspectos que selecionei da crítica produzida no Brasil para este estudo encontram em declarações do próprio autor Franz Kafka um apoio, pois uma admiração tão grande e tão bem documentada certamente contribuiu para que Franz Kafka elaborasse sua própria literatura com algo de kleistiano.

\section{Referências bibliográficas}

Carpeaux, Otto Maria. Literatura Alemã (pref. de Willi Bolle). São Paulo, Nova Alexandria, 1994, 102-105.

Carpeaux, Otto Maria. "Franz Kafka e o mundo invisível”. In: A Cinza do Purgatório. Rio de Janeiro, 1942, 150-161.

Carpeaux, Otto Maria. "Novelas Exemplares". In: Livros na Mesa. Rio de Janeiro, Livraria São José, 1950, 43-49.

Hermes, Roger/ JoHn, Waltraud/ KoCH, Hans-Gerd/ WiderA, Anita (org.). Franz Kafka - Eine Chronik. Berlin, Klaus Wagenbach Verlag, 1999.

KAFKA, Franz. Briefe 1902 - 1924 (org. por Max BROD). Frankfurt am Main: Fischer, 1998.

KAFKA, Franz. Briefe an Felice (organizado por Erich HELLER e Jürgen BORN). Frankfurt am Main: Fischer Taschenbuch Verlag, 2003.

KLEIST, Heinrich von. „Erzählungen und Anekdoten: Michael Kohlhaas“ (Aus einer alten Chronik). In: Sämtliche Werke und Briefe. München, dtv, 2001, 1-103.

LimA, Luiz Costa. Limites da voz: Kafka. Rio de Janeiro, Rocco, 1993. 